\title{
Mental Well-Being and Self-Efficacy of Healthcare Workers in Saudi Arabia During the COVID-19 Pandemic
}

\author{
Ehab A Abo-Ali (D) ${ }^{1,2}$ \\ Shayma Al-Rubaki ${ }^{3}$ \\ Sarah Lubbad ${ }^{3}$ \\ Manal Nchoukati ${ }^{3}$ \\ Rana Alqahtani ${ }^{3}$ \\ Sahar Albraim ${ }^{3}$ \\ Wessam A Ghareeb ${ }^{4}$ \\ Badr Al-Haffashi ${ }^{5}$ \\ Faisal Alghamdi ${ }^{6}$ \\ Sameh Zaytoun (D) $^{7}$
}

'Community Medicine Department, Faculty of Medicine, University of Tanta, Tanta, 31527, Egypt; ${ }^{2}$ Community Medicine Department, Batterjee Medical College, Jeddah, 21442, Saudi Arabia; ${ }^{3}$ Medicine Program, Batterjee Medical College, Jeddah, 21442, Saudi Arabia;

${ }^{4}$ Neuro-Psychiatry Department, Faculty of Medicine, University of Tanta, Tanta, 31527, Egypt; ${ }^{5}$ Internal Medicine

Department, King Abdulaziz Hospital, Makkah, Saudi Arabia; ${ }^{6}$ Internal Medicine Department, King Fahd Hospital, Albaha, Saudi Arabia; ${ }^{7}$ Department of Community Medicine, Faculty of Medicine, South Valley University, Qena, Egypt
Correspondence: Ehab A Abo-Ali Tanta Faculty of Medicine, Tanta, 31527, Egypt

Tel +20I00I532068; +966 542538464

Fax +20403407734

Email ehab.abouly@bmc.edu.sa;

ehababoali8@gmail.com
Purpose: To assess mental well-being (MW), self-efficacy (SE), and their predictors among healthcare workers (HCWs) in Saudi Arabia during the COVID-19 pandemic.

Methods: Analytical cross-sectional study recruited $1046 \mathrm{HCWs}$ by cluster random sampling technique. Socio-demographic, health, and occupational characteristics were collected for all participants. The WHO five Well-Being Index (WHO-5) and General Self-Efficacy Scale (GSES) were used to assess MW and SE of the participants, respectively. The binary logistic regression model was fit to the dependent (outcomes), namely mental well-being and self-efficacy, and independent other variables (predictors).

Results: Out of all participants ( $n=1046), 27.2 \%$ had negative MW scores, and $36.6 \%$ had low SE scores. The mean scores of both MW and SE were in the normal levels $(16.7 \pm 5.90$ and $31.5 \pm 6.63$ out of 25 and 40, respectively). Younger and older ages, irregular exercise, nursing professions, history of anxiety and/or depression, lesser years of experience, and longer daily working hours were found to be the main predictors of negative MW and low SE, among study participants.

Conclusion: Mental well-being (MW) and self-efficacy (SE) of the HCWs in Saudi Arabia are satisfactory but attention should be paid towards supporting the vulnerable groups for promoting the resilience of HCWs during the battle against the current pandemic.

Keywords: mental well-being, self-efficacy, healthcare workers, Saudi Arabia, COVID-19, predictors

\section{Introduction}

The Coronavirus disease 2019 (COVID-19) was first reported in Wuhan city in China on December 2019, before it spread to the rest of the world. ${ }^{1}$ COVID-19 is an emergency respiratory disease that causes illnesses ranging from the common cold to severe acute respiratory syndrome (SARS) and is transmitted via human-tohuman contact. ${ }^{2}$ It was declared a pandemic by the World Health Organization (WHO) on 11th March 2020. ${ }^{3}$ Saudi Arabia announced its first COVID-19 case on 2nd March 2020 with the total number of confirmed cases reaching 371,356 and a recovery rate of $97.58 \%$ as of 11 th February $2021 .^{4,5}$ The pandemic and its associated circumstances have a profound social, mental, physical, psychological, and economic impact on all people around the world. ${ }^{6}$ The healthcare workers (HCWs), the frontline warriors of this crisis, have a higher potential of negative effects on their mental health and self-efficacy. ${ }^{7}$

According to WHO, mental health is defined as 
A state of well-being in which the individuals realize their abilities, can cope with the normal life stresses, can work productively and can make a contribution to their community. ${ }^{8}$

Among the spectrum of challenges HCWs face during a global outbreak, various factors like increased workload or work hours, scarcity of personal protective equipment, over-enthusiastic media news, feeling inadequately supported, and the high infection rate among medical staff, all have contributed to the dramatic effect on their performance and well-being. ${ }^{9}$ Poor mental well-being is in turn linked to decreased quality of patient care and medical errors. ${ }^{10}$ In previous outbreaks like the Ebola virus and SARS, it is reported that HCWs have suffered from mental distress. ${ }^{11}$ Consequently, similar concerns are now arising with regard to the mental well-being of HCWs during the COVID-19 pandemic. A recent Chinese study showed that a noteworthy proportion of HCWs treating COVID-19 patients revealed symptoms of depression, anxiety, insomnia, and distress. ${ }^{12}$ Similarly, a study conducted in Oman in 2020 revealed that the pandemic has impacted the mental health of younger female physicians compared to other groups. $^{13}$

Self-efficacy generally predicts one's ability to cope with daily challenges and adapt after confronting stressful events. ${ }^{14}$ It is an integral factor that allocates the level of self-confidence, thought process, and subsequent accomplishments of a person. ${ }^{15}$ Improved self-efficacy is predictive of better mental well-being, personal accomplishments, and lower levels of emotional exhaustion among HCWs. ${ }^{16}$ In general, there is an association between levels of problem-oriented coping strategy, general self-efficacy, and internal locus of control, and mental health. ${ }^{17}$ Milam et al described that among other factors, self-efficacy appears to be significantly predictive of wellbeing. High self-efficacy provides the feeling of well prepared and capable. ${ }^{16}$

During global health emergencies, assessing of the mental well-being and self-efficacy of the HCWs is a priority to avoid the breakdown of the treasured manpower in the healthcare system. The current study aimed to assess mental well-being (MW) and self-efficacy (SE) and their predictors among healthcare workers (HCWs) in Saudi Arabia during the COVID-19 pandemic.

\section{Methods}

Study Design

Analytical cross-sectional study.

\section{Study Setting}

This study was conducted in Saudi Arabia from August to December 2020. The healthcare system in Saudi Arabia is composed mainly of the public sector (with its three levels of care; primary, secondary and tertiary), and the private sector which provides secondary and tertiary care. The main burden of COVID-19 management is carried out by the public sector.

\section{Study Population and Sampling Technique}

All healthcare workers in Saudi Arabia were eligible to be included in the study. The sample size was determined to be 384 , assuming a $50 \%$ prevalence of both positive mental well-being and good self-efficacy, a precision of $5 \%$, and a confidence level of $95 \%$. The sample size was enlarged for more accuracy of results and more study power. A cluster random sampling technique was used for the collection of the study sample. Every cluster included all healthcare workers in the selected healthcare setting. The number of clusters was assigned by the proportional allocation technique considering the differences in HCWs distribution among administrative areas all over the country. Each cluster was composed of front-line HCWs (physicians and nurses) in addition to other health care workers (paramedics, technicians, administrates, etc.). The Study questionnaire was provided to study participants either in Arabic or English versions according to their preferences. The questionnaire responses were submitted through different online platforms (such as e-mail, WhatsApp, Twitter, Facebook). Only one online platform was used for the participants of the same cluster to avoid double responses. Also, the questionnaire was designed as not to accept more than one response from the same participant. Out of the 1078 approached HCWs, 1046 agreed to participate in the study, with a response rate of $97 \%$.

\section{Study Tool}

For every study participant, the following data were collected through a self-administered questionnaire that included the following sections:

(i) Socio-demographic, health, and occupational characteristics; The following variables were adopted from previous studies with some modifications. $^{12,16,18}$ Age, gender, nationality, smoking status, chronic health condition, history 
of anxiety and/or depression, profession, hospital type, Corona team membership, experience, years of experience and working hours per day were inquired about.

(ii) WHO five Well-Being Index (WHO-5): This scale was used to assess the current mental well-being over the last two weeks. It is composed of five statements and the response to every statement is graded over a six-grade Likert scale ranging from (At no time $=0$ ) to (All of the time $=5$ ). The total score ranges between 0 and 25 indicating the worst and the best mental well-being status, respectively. The WHO-5 index uses only positively phrased sentences such as "I have felt cheerful and in good spirits" and "I have felt calm and relaxed", for the avoidance of symptom-related language. The WHO-5 index has a cutoff point at a total score of 13. Scores below 13 represent a state of negative mental well-being. The WHO-5 index is one of the most commonly used tools for the assessment of subjective mental well-being and has been used in many studies worldwide. ${ }^{19}$

(iii) General Self-Efficacy Scale (GSES): This scale was developed for the assessment of the general sense of perceived self-efficacy aiming to predict coping with daily struggles as well as the ability to adapt after confronting all kinds of stressful daily events. The scale is composed of 10 items with a response grade ranging from 1 (Not at all true) to 4 (Exactly true) on a four-grade Likert scale. Example of the statements as "I can always manage to solve difficult problems if I try hard enough". The total score ranges between 10 and 40 with higher scores indicating higher self-efficacy. Low self-efficacy is assigned to scores below 30. The GSES has been used in many studies and proved validity and reliability in more than 30 languages. ${ }^{14,20}$

\section{Ethical Considerations}

Approval with an ID (UB-RES-2020-0054) from the Ethics and Scientific Committees of Batterjee Medical College was obtained before conducting the study. The study was conducted following the Declaration of Helsinki. Informed consent was obtained from all participants; the aim of the study was clearly explained and the icon of "Agree to participate" was a condition for proceeding with responding to the questionnaire items. The provision of the participant's name was optional and confidential. The names of the healthcare settings were kept confidential. Confidentiality of the whole collected data was assured and guaranteed.

\section{Data Analysis}

The collected data was statistically analyzed using the statistical package for social studies (SPSS) version 23 created by IBM, Chicago, IL, USA. Categorical variables were presented as numbers and percentages. The numerical variables were presented as mean \pm standard deviation. The binary logistic regression model was fit to the dependent (outcomes) namely Mental Well-being and Self-efficacy, and independent (predictors) other variables. The model was evaluated for the prediction and estimation of the outcomes. For individual predictors, if the p-value is $<0.05$ at the $95 \%$ confidence of interval, this variable is statistically significant in the model and is likely to affect the probability of the binomial outcome.

\section{Results}

The present study included 1046 of the HCWs in Saudi Arabia, with a mean age of $35.4 \pm 9.72$. Both genders were nearly equally represented. Nearly two-thirds of the participants (64.5\%) were aged between 30 and 50 years old, more than four-fifths of them were Saudis, more than half $(60.3 \%)$ were married, and more than one-third (35.1\%) were current smokers. Less than one-third of the participants $(29.2 \%)$ practiced regular exercise. The majority of the participants $(85.4 \%)$ were not having any chronic medical condition, and about one-fifth of them (19.7\%) reported a history of anxiety and/or depression. More than half of the participants $(55.9 \%)$ were physicians, and $56.7 \%$ of them were general practitioners. The majority of the participants were working at public hospitals; more than half of them (56.5\%) were Corona Care Team members. Nearly two-thirds of the study participants had at least five years of experience and half of them had to work more than 8 hours per day. (Table 1)

The present study revealed that more than fourth of the HCWs (27.2\%) had negative MW scores, while more than a third of them (36.6\%) had low SE scores. The mean scores of both MW and SE were in the normal levels (16.7 and 31.5 , respectively). (Table 2)

Considering the Exp. (B), an odds ratio of 1 was considered as a reference value with no effect. An odds ratio of more than 1 indicates that this variable increases the odds of the dependent outcome, and vice versa. The 
Table I Socio-Demographic, Health, and Occupational Characteristics of HCWs Participants in Saudi Arabia $(n=1046)$

\begin{tabular}{|c|c|c|}
\hline \multirow[t]{2}{*}{ Variables } & \multicolumn{2}{|c|}{ Study Participants $(n=1046)$} \\
\hline & No. & $\%$ \\
\hline \multicolumn{3}{|l|}{ Gender: } \\
\hline Male & 526 & 50.3 \\
\hline Female & 520 & 49.7 \\
\hline \multicolumn{3}{|c|}{ Age in years: $($ mean $\pm S D=35.4 \pm 9.72)$} \\
\hline \multicolumn{3}{|l|}{ Age group: } \\
\hline$<30$ & 265 & 25.3 \\
\hline $30-$ & 674 & 64.5 \\
\hline 50 and more & 107 & 10.2 \\
\hline \multicolumn{3}{|l|}{ Nationality } \\
\hline Saudi & 847 & 81.0 \\
\hline Non-Saudi & 199 & 19.0 \\
\hline \multicolumn{3}{|l|}{ Marital status } \\
\hline Married & 631 & 60.3 \\
\hline Unmarried & 415 & 39.7 \\
\hline \multicolumn{3}{|l|}{ Smoking } \\
\hline Yes & 367 & 35.1 \\
\hline No & 679 & 64.9 \\
\hline \multicolumn{3}{|l|}{ Regular exercise } \\
\hline Yes & 305 & 29.2 \\
\hline No & 741 & 70.8 \\
\hline \multicolumn{3}{|l|}{ Chronic conditions } \\
\hline Yes & 153 & 14.6 \\
\hline No & 893 & 85.4 \\
\hline \multicolumn{3}{|c|}{ History of anxiety and/or depression? } \\
\hline Yes & 206 & 19.7 \\
\hline No & 840 & 80.3 \\
\hline \multicolumn{3}{|l|}{ Profession } \\
\hline Physician & 585 & 55.9 \\
\hline Nurse & 331 & 31.6 \\
\hline Other & 130 & 12.4 \\
\hline \multicolumn{3}{|l|}{ Qualifications } \\
\hline General practitioner & 593 & 56.7 \\
\hline Specialist & 358 & 34.2 \\
\hline Consultant & 95 & 9.1 \\
\hline \multicolumn{3}{|l|}{ Hospital type } \\
\hline Public & 912 & 87.2 \\
\hline Private & 134 & 12.8 \\
\hline
\end{tabular}

(Continued)
Table I (Continued).

\begin{tabular}{|l|c|c|}
\hline \multirow{2}{*}{ Variables } & \multicolumn{2}{|c|}{ Study Participants (n=1046) } \\
\cline { 2 - 3 } & No. & $\%$ \\
\hline Corona Care Team member & 56.5 \\
\hline Yes & 591 & 43.5 \\
No & 455 & \\
\hline Years of experience & & 36.9 \\
\hline Less than 5 years & 386 & 36.5 \\
5 to 9 years & 382 & 26.6 \\
10 years and more & 278 & \\
\hline Working hours per day & \multicolumn{2}{|c|}{} \\
\hline 8 or below & 520 & 59.7 \\
More than 8 & 526 & \\
\hline
\end{tabular}

present study showed that middle-aged HCWs are less likely to have a positive MW state compared to younger and older age groups $(\mathrm{OR}=0.47,95 \% \mathrm{CI}$ : $0.28,0.78)$. Current non-smokers are less likely to have a positive MW compared to current smokers $(\mathrm{OR}=0.67,95 \% \mathrm{CI}$ : $0.48,0.95)$. The participants with no regular exercise habit are less likely to have a positive MW compared to those having regular exercise $(\mathrm{OR}=0.41,95 \% \mathrm{CI}: 0.29,0.60)$. HCWs with no history of anxiety and/or depression are 2.15 times more likely to have positive MW than those having a history of these conditions $(\mathrm{OR}=2.15,95 \% \mathrm{CI}$ : $1.43,3.24)$. Nurses and other HCWs are less likely to be in a positive $\mathrm{MW}$ compared to physicians $(\mathrm{OR}=0.54$ and $0.37,95 \%$ CI: $0.38,0.78$ and $0.23,0.59$, respectively). The

Table 2 Mental Well-Being (MW) and Self Efficacy (SE) Scores Among the HCWs in Saudi Arabia During the COVID-19 Pandemic

\begin{tabular}{|l|c|c|c|c|}
\hline \multirow{2}{*}{} & \multicolumn{2}{|c|}{$\begin{array}{c}\text { MW Scores of HCWs } \\
(\mathrm{n}=1046)\end{array}$} & \multicolumn{2}{c|}{$\begin{array}{r}\text { SE Scores of HCWs } \\
(\mathrm{n}=1046)\end{array}$} \\
\cline { 2 - 5 } & $\begin{array}{c}\text {-ve MW } \\
\text { No. (\%) }\end{array}$ & $\begin{array}{r}\text { +ve MW } \\
\text { No. (\%) }\end{array}$ & $\begin{array}{r}\text { Low SE } \\
\text { No. (\%) }\end{array}$ & $\begin{array}{r}\text { High SE } \\
\text { No. (\%) }\end{array}$ \\
\hline & $284(27.2)$ & $762(72.8)$ & $383(36.6)$ & $663(63.4)$ \\
\hline Range & \multicolumn{2}{|c|}{$0-25$} & \multicolumn{2}{|c|}{$10-40$} \\
\hline Mean & \multicolumn{2}{|c|}{$16.7 \pm 5.90$} & \multicolumn{2}{|c|}{$31.5 \pm 6.53$} \\
\pm SD & \multicolumn{2}{|c|}{17.0} & \multicolumn{2}{|c|}{32.0} \\
\hline Median & \multicolumn{2}{|c|}{17.0} \\
\hline
\end{tabular}


HCWs employed in a private hospital are more likely to have positive MW compared to those employed in public ones $(\mathrm{OR}=2.09,95 \% \mathrm{CI}: 1.25,3.49)$. HCWs with moderate and long years of experience are more likely to have positive MW compared to their colleges with lesser years of experience $(\mathrm{OR}=3.97$ and 2.55, 95\% CI: 2.60, 6.06 and $1.49,4.34$, respectively). Participants who reported that they have been working more than 8 hours per day are less likely to have positive MW compared to those working for 8 hours or less $(\mathrm{OR}=0.68,95 \% \mathrm{CI}$ : $0.49,0.93)$. Other factors such as gender, age in years, nationality, marital status, chronic health conditions, qualifications, and Corona Team membership, were found not to significantly affect the MW state among study participants. (Table 3)

Concerning the Self Efficacy scores among HCWs, the present study revealed that middle-aged $\mathrm{HCWs}$ are more likely to have higher SE compared to younger HCWs $(\mathrm{OR}=1.61,95 \%$ CI: 1.03, 2.52). Non-Saudi HCWs are more likely to have higher SE compared to Saudi colleagues $(\mathrm{OR}=1.64,95 \%$ CI: 1.11, 2.42). Additionally, HCWs without chronic medical conditions are more likely to have higher SE than their peers who suffer from a chronic condition (OR=1.65, 95\% CI: 1.11, 2.46). Similarly, HCWs with no history of anxiety and/or depression were found to be more likely to have higher SE compared to those with history of these conditions $(\mathrm{OR}=1.58,95 \% \mathrm{CI}: 1.12,2.23)$. Specialists HCWs are more likely to have better SE scores compared to general practitioners ( $\mathrm{OR}=1.62,95 \% \mathrm{CI}: 1.20,2.18)$. The HCWs who are not members of the Corona Care Team were found to be less likely to have high SE scores compared to those who are members of the Corona Care Team $(\mathrm{OR}=0.66$, $95 \%$ CI: 0.50, 0.87). Participants who reported that they are working more than 8 hours per day are less likely to have high SE scores compared to those working for 8 hours or less $(\mathrm{OR}=0.76,95 \% \mathrm{CI}: 0.58,0.99)$. Other factors such as gender, age, marital status, current smoking, practicing regular exercise, profession, hospital type, and years of experience, were found not to significantly affect the SE scores among study participants. (Table 4)

\section{Discussion}

With the ongoing COVID-19 pandemic, HCWs are facing a spectrum of challenges that can eventually take a toll on their MW. Poor MW of HCWs has been associated with less favorable quality of patient care. ${ }^{10}$
The current study showed no significant relationship between MW and the gender of the HCWs. This is in contrast to a study by Badahdah et al, in which the female physicians experienced decreased mental well-being throughout the pandemic compared to male physicians. ${ }^{13}$ Nevertheless, this study revealed lower levels of MW among healthcare workers in the middle age group that could be attributed to the fear of carrying the infection to their families and the traditionally increased responsibility and workload on middle-aged $\mathrm{HCWs}$, compared to their colleagues of other ages. This is in concordance with a study by Rahman et al, while another study in Oman reported that younger physicians experienced decreased MW. ${ }^{13,21}$

Surprisingly, the present study revealed that HCWs who are current smokers tend to have positive MW. This could be explained as smoking may be may have been utilized as a maladaptive stress-coping behavior throughout the pandemic. ${ }^{21}$ On the contrary, HCWs who exercise regularly have shown more positive MW. This can be an example of a healthy and effective stress-coping mechanism that has been adopted. HCWs with no history of anxiety and/or depression have shown significantly better MW status, compared to others with history of such problems. Previous episodes of anxiety and/or depression have been shown to play a part in intensifying predisposition to anxiety disorders with unprecedented stress. ${ }^{21,22}$

Nurses showed more tendency to negative MW state compared to other HCWs. Similar studies conducted in China and Nepal found that the highest prevalence of anxiety, insomnia symptoms were observed in nurses more than in other HCWs. ${ }^{12,23}$ This might be because of the higher workload and the greater risk of direct contact to patients with COVID-19. Similarly, a study in Hong Kong revealed that HCWs had higher levels of depression, anxiety and post-traumatic stress compared to non-HCWs one year after the SARS outbreak. ${ }^{24}$

The current study revealed that increased working hours of HCWs is associated with more negative MW status. This is in agreement with a systematic review study by Schneider et al, and another study by Spoorthy et al, who reported that excessive workload and working hours are possible reasons for the adverse psychological outcomes seen in HCWs. Additionally, Spoorthy et al found that $\mathrm{HCWs}$ who served in public hospitals have less positive MW than those who served in private ones. This was expected due to higher workloads, and as most of the COVID-19 patients are referred to public hospitals. ${ }^{9}$

The current study revealed no significant association between the gender of HCWs and their SE levels. This is 
Table 3 Binary Logistic Regression of Mental Well-Being Scores Among the HCWs in Saudi Arabia During the COVID-I9 Pandemic

\begin{tabular}{|c|c|c|c|c|c|c|c|c|}
\hline \multirow[t]{2}{*}{ Variables } & \multirow[t]{2}{*}{ B } & \multirow[t]{2}{*}{ S.E. } & \multirow[t]{2}{*}{ Wald } & \multirow[t]{2}{*}{ df } & \multirow[t]{2}{*}{ Sig. } & \multirow[t]{2}{*}{ Exp. (B) } & \multicolumn{2}{|c|}{ 95\% C.I. for $\operatorname{EXP}(B)$} \\
\hline & & & & & & & Lower & Upper \\
\hline \multicolumn{9}{|l|}{ Gender: } \\
\hline Male (ref) & & & & & & I & & \\
\hline Female & -0.118 & 0.167 & 0.497 & I & $0.48 I$ & 0.89 & 0.64 & 1.23 \\
\hline Age in years: & 0.022 & 0.020 & 1.125 & 1 & 0.289 & 1.02 & 0.98 & 1.06 \\
\hline \multicolumn{9}{|l|}{ Age groups: } \\
\hline$<30$ (ref) & & & 16.511 & 2 & $0.000 *$ & I & & \\
\hline $30-$ & -0.754 & 0.259 & 8.500 & $\mathrm{I}$ & $0.004^{*}$ & 0.47 & 0.28 & 0.78 \\
\hline$\geq 50$ & 0.148 & 0.649 & 0.052 & 1 & 0.819 & 1.16 & 0.33 & 4.14 \\
\hline \multicolumn{9}{|l|}{ Nationality: } \\
\hline Saudi (ref) & & & & & & I & & \\
\hline Non-Saudi & -0.368 & 0.205 & 3.223 & I & 0.073 & 0.69 & 0.46 & 1.03 \\
\hline \multicolumn{9}{|l|}{ Marital status: } \\
\hline Married (ref) & & & & & & I & & \\
\hline Unmarried & -0.180 & 0.177 & 1.027 & 1 & 0.311 & 0.84 & 0.59 & 1.18 \\
\hline \multicolumn{9}{|l|}{ Currently smoking: } \\
\hline Yes (ref) & & & & & & I & & \\
\hline No & -0.395 & 0.177 & 4.991 & I & $0.025^{*}$ & 0.67 & 0.48 & 0.95 \\
\hline \multicolumn{9}{|l|}{ Regular exercise: } \\
\hline Yes (ref) & & & & & & I & & \\
\hline No & -0.882 & 0.189 & 21.691 & I & $0.000 *$ & 0.41 & 0.29 & 0.60 \\
\hline \multicolumn{9}{|l|}{ Chronic conditions: } \\
\hline Yes (ref) & & & & & & I & & \\
\hline No & -0.513 & 0.272 & 3.553 & $\mathrm{I}$ & 0.059 & 0.60 & 0.35 & 1.02 \\
\hline \multicolumn{9}{|c|}{ History of anxiety and/or depression: } \\
\hline Yes (ref) & & & & & & I & & \\
\hline No & 0.766 & 0.209 & $|3.46|$ & I & $0.000^{*}$ & 2.15 & 1.43 & 3.24 \\
\hline \multicolumn{9}{|l|}{ Profession: } \\
\hline Physician (ref) & & & 22.440 & 2 & 0.000 & I & & \\
\hline Nurse & -0.610 & 0.183 & 11.101 & 1 & $0.001 *$ & 0.54 & 0.38 & 0.78 \\
\hline Other & -0.990 & 0.237 & 17.414 & I & $0.000 *$ & 0.37 & 0.23 & 0.59 \\
\hline \multicolumn{9}{|l|}{ Qualifications: } \\
\hline General practitioner (ref) & & & 4.697 & 2 & 0.096 & I & & \\
\hline Specialist & -0.315 & 0.171 & 3.385 & I & 0.066 & 0.73 & 0.52 & 1.02 \\
\hline Consultant & -0.524 & 0.344 & 2.313 & I & 0.128 & 0.59 & 0.30 & 1.16 \\
\hline
\end{tabular}

(Continued) 
Table 3 (Continued).

\begin{tabular}{|c|c|c|c|c|c|c|c|c|}
\hline \multirow[t]{2}{*}{ Variables } & \multirow[t]{2}{*}{ B } & \multirow[t]{2}{*}{ S.E. } & \multirow[t]{2}{*}{ Wald } & \multirow[t]{2}{*}{ df } & \multirow[t]{2}{*}{ Sig. } & \multirow[t]{2}{*}{ Exp. (B) } & \multicolumn{2}{|c|}{ 95\% C.I. for $\operatorname{EXP}(B)$} \\
\hline & & & & & & & Lower & Upper \\
\hline \multicolumn{9}{|l|}{ Hospital type: } \\
\hline Public (ref) & & & & & & I & & \\
\hline Private & 0.736 & 0.262 & 7.900 & 1 & $0.005^{*}$ & 2.09 & 1.25 & 3.49 \\
\hline \multicolumn{9}{|c|}{ Corona Care Team member: } \\
\hline Yes (ref) & & & & & & I & & \\
\hline No & 0.133 & 0.159 & 0.704 & 1 & 0.401 & 1.14 & 0.84 & 1.56 \\
\hline \multicolumn{9}{|l|}{ Years of experience: } \\
\hline Less than 5 years (ref) & & & 40.772 & 2 & 0.000 & I & & \\
\hline 5 to 9 years & 1.378 & 0.216 & 40.740 & 1 & $0.000 *$ & 3.97 & 2.60 & 6.06 \\
\hline 10 years and more & 0.934 & 0.273 & 11.750 & 1 & $0.001 *$ & 2.55 & 1.49 & 4.34 \\
\hline \multicolumn{9}{|c|}{ Working hours per day: } \\
\hline 8 or less (ref) & & & & & & I & & \\
\hline More than 8 & -0.391 & 0.161 & 5.863 & 1 & $0.015^{*}$ & 0.68 & 0.49 & 0.93 \\
\hline Constant & 1.570 & 0.743 & 4.463 & I & $0.035^{*}$ & 4.81 & & \\
\hline
\end{tabular}

Note: *Significant statistical difference.

a concordance with a similar study for evaluating the status of depression and SE among medical residents in China. ${ }^{25}$ The middle age group showed higher SE compared to other age groups. This is in disagreement with a study by Shoji et al, who reported that SE-burnout associations were stronger among older workers, compared to younger ones. ${ }^{26}$

This study revealed that non-Saudi HCWs in Saudi Arabia had higher levels of SE compared to Saudis. This finding can be due to underlying factors including the workplace environment, the level of social anxiety, communication skills, and the type of patients. A study of 200 family medicine residents in Riyadh, Saudi Arabia showed that low levels of SE were related to high levels of social anxiety. ${ }^{15}$ Besides, another study reported relatively lower SE among 1000 dentists when treating adult patients with mental and physical disabilities. ${ }^{18}$ Studies in Norway and United States exhibited improved SE among doctors after completing a communication skills training course. ${ }^{27,28} \mathrm{On}$ the other hand, marital status, smoking, and regular exercise showed no significant relationship with the level of SE among HCWs.

The current study showed that HCWs who suffered from anxiety and/or depression are more susceptible to lower SE. This is in agreement with Maryam et al who reported that HCWs who suffer from anxiety, depression, insomnia, fear, and low sleep quality are significantly associated with low SE. This could be explained through the perspective that $\mathrm{HCW}$ s have a higher risk of acquiring COVID-19 infection in comparison to the general population in addition to the stressful nature of their jobs. ${ }^{29}$ On the other side, the present study showed no significant association between the history of chronic diseases with neither MW nor SE.

Our study showed no significant relationship between hospital type and SE. This is in disagreement with another study in Kenya, where the public professional health workers showed lower SE than their counterparts in private facilities. However, the aforementioned study revealed similar results to our study regarding the relationship between the profession and SE. ${ }^{30}$

The current study showed that years of experience is not a predictor of for HCWs' SE. This could be justified by the unprecedented nature of the pandemic for all. In contrast, a similar study in Iran revealed a distinction between nurses' SE and their years of experience. ${ }^{31}$

The present study demonstrated higher levels of SE among Corona team members compared to the rest of the HCWs. This could be attributed to the high social and official support for the Corona team members in Saudi 
Table 4 Binary Logistic Regression of Self Efficacy Scores Among the HCWs in Saudi Arabia During the COVID-19 Pandemic

\begin{tabular}{|c|c|c|c|c|c|c|c|c|}
\hline \multirow[t]{2}{*}{ Variables } & \multirow[t]{2}{*}{ B } & \multirow[t]{2}{*}{ S.E. } & \multirow[t]{2}{*}{ Wald } & \multirow[t]{2}{*}{ df } & \multirow[t]{2}{*}{ Sig. } & \multirow[t]{2}{*}{ Exp. (B) } & \multicolumn{2}{|c|}{ 95\% C.I. for $\operatorname{EXP}(B)$} \\
\hline & & & & & & & Lower & Upper \\
\hline \multicolumn{9}{|l|}{ Gender: } \\
\hline Male (ref) & & & & & & I & & \\
\hline Female & -0.046 & 0.148 & 0.099 & I & 0.753 & 0.96 & 0.72 & 1.28 \\
\hline Age in years: & -0.017 & 0.016 & 1.117 & I & 0.291 & 0.98 & 0.95 & 1.02 \\
\hline \multicolumn{9}{|l|}{ Age groups: } \\
\hline$<30$ (ref) & & & 4.835 & 2 & 0.089 & 1 & & \\
\hline $30-$ & 0.477 & 0.229 & 4.331 & I & $0.037^{*}$ & 1.61 & 1.03 & 2.52 \\
\hline$\geq 50$ & 1.023 & 0.527 & 3.771 & 1 & 0.052 & 2.78 & 0.99 & 7.81 \\
\hline \multicolumn{9}{|l|}{ Nationality: } \\
\hline Saudi (ref) & & & & & & 1 & & \\
\hline Non-Saudi & 0.494 & 0.199 & 6.165 & I & $0.013^{*}$ & 1.64 & I.II & 2.42 \\
\hline \multicolumn{9}{|l|}{ Marital status: } \\
\hline Married (ref) & & & & & & 1 & & \\
\hline Unmarried & 0.120 & 0.160 & 0.560 & 1 & 0.454 & 1.13 & 0.82 & 1.54 \\
\hline \multicolumn{9}{|l|}{ Currently smoking: } \\
\hline Yes (ref) & & & & & & I & & \\
\hline No & 0.046 & 0.150 & 0.092 & 1 & 0.761 & 1.05 & 0.78 & $1.4 \mathrm{I}$ \\
\hline \multicolumn{9}{|l|}{ Regular exercise: } \\
\hline Yes (ref) & & & & & & I & & \\
\hline No & 0.168 & 0.148 & 1.289 & I & 0.256 & 1.18 & 0.89 & 1.58 \\
\hline \multicolumn{9}{|l|}{ Chronic conditions: } \\
\hline Yes (ref) & & & & & & 1 & & \\
\hline No & 0.501 & 0.203 & 6.124 & I & $0.013^{*}$ & 1.65 & I.II & 2.46 \\
\hline \multicolumn{9}{|c|}{ History of anxiety and/or depression: } \\
\hline Yes (ref) & & & & & & 1 & & \\
\hline No & 0.456 & 0.176 & 6.763 & 1 & $0.009 *$ & 1.58 & 1.12 & 2.23 \\
\hline \multicolumn{9}{|l|}{ Profession: } \\
\hline Physician (ref) & & & 1.430 & 2 & 0.489 & 1 & & \\
\hline Nurse & 0.118 & 0.163 & 0.524 & 1 & 0.469 & 1.13 & 0.82 & 1.55 \\
\hline Other & 0.244 & 0.225 & 1.181 & 1 & 0.277 & 1.28 & 0.82 & 1.98 \\
\hline \multicolumn{9}{|l|}{ Qualifications: } \\
\hline General practitioner (ref) & & & 9.876 & 2 & $0.007^{*}$ & I & & \\
\hline Specialist & 0.480 & 0.153 & 9.816 & I & $0.002^{*}$ & 1.62 & 1.20 & 2.18 \\
\hline Consultant & 0.158 & 0.280 & 0.318 & 1 & 0.573 & 1.17 & 0.68 & 2.03 \\
\hline
\end{tabular}

(Continued) 
Table 4 (Continued).

\begin{tabular}{|c|c|c|c|c|c|c|c|c|}
\hline \multirow[t]{2}{*}{ Variables } & \multirow[t]{2}{*}{ B } & \multirow[t]{2}{*}{ S.E. } & \multirow[t]{2}{*}{ Wald } & \multirow[t]{2}{*}{ df } & \multirow[t]{2}{*}{ Sig. } & \multirow[t]{2}{*}{ Exp. (B) } & \multicolumn{2}{|c|}{ 95\% C.I. for $\operatorname{EXP}(B)$} \\
\hline & & & & & & & Lower & Upper \\
\hline \multicolumn{9}{|l|}{ Hospital type: } \\
\hline Public (ref) & & & & & & 1 & & \\
\hline Private & 0.373 & 0.218 & 2.920 & 1 & 0.087 & 1.45 & 0.95 & 2.23 \\
\hline \multicolumn{9}{|c|}{ Corona Care Team member: } \\
\hline Yes (ref) & & & & & & 1 & & \\
\hline No & -0.416 & 0.139 & 8.989 & 1 & $0.003 *$ & 0.66 & 0.50 & 0.87 \\
\hline \multicolumn{9}{|l|}{ Years of experience: } \\
\hline Less than 5 years (ref) & & & 3.710 & 2 & 0.156 & I & & \\
\hline 5 to 9 years & -0.236 & 0.193 & 1.506 & I & 0.220 & 0.79 & 0.54 & 1.15 \\
\hline 10 years and more & 0.129 & 0.250 & 0.268 & 1 & 0.605 & 1.14 & 0.70 & 1.86 \\
\hline \multicolumn{9}{|c|}{ Working hours per day: } \\
\hline 8 or below (ref) & & & & & & I & & \\
\hline More than 8 & -0.279 & 0.139 & 3.998 & I & $0.046^{*}$ & 0.76 & 0.58 & 0.99 \\
\hline Constant & -0.205 & 0.593 & 0.120 & 1 & 0.729 & 0.81 & & \\
\hline
\end{tabular}

Note: *Significant statistical difference.

Arabia. The HCWs in our study who worked more than 8 hours per day had lower SE compared to their counterparts who worked 8 hours or less. This is in line with a study conducted among vascular surgeons in the United States. ${ }^{32}$

The current study is one of the first to explore the MW and SE of HCWs in Saudi Arabia during the current COVID-19 pandemic. It serves as a baseline for followup of the mental resilience of the HCWs during the course of the pandemic. Furthermore, the study revealed some unexpected predictors of MW and SE, which may be a base for future researches. The limitation of this study is that HCWs who do not have access to the internet and those who are not familiar with online platforms, were not represented in the study.

\section{Conclusion}

With the current COVID-19 pandemic, healthcare workers (HCWs) face a broad range of difficulties that can ultimately impact their mental well-being (MW) and selfefficacy (SE), which could contribute to a lower quality of patient care. The key predictors of negative MW and low SE among the HCWs were found to be: age extremes, irregular exercisers, nursing professions, history of anxiety and/or depression, lesser years of experience, and longer daily working hours. In Saudi Arabia, the mental wellbeing (MW) and self-efficacy (SE) of HCWs are satisfactory but attention should be paid to helping in promoting the resilience of the vulnerable groups during the fight against the current pandemic. Future research is needed for to evaluate the effectiveness of MW and SE promoting programs provided to HCWs.

\section{Ethical Approval}

Approval with an ID (UB-RES-2020-0054) from the Ethics and Scientific Committees of Batterjee Medical College was obtained before the conduction of the study. Confidentiality of the collected data, the names of the participants, and their respective healthcare settings were guaranteed.

\section{Informed Consent}

Informed consent was obtained from all participants; the aim of the study was clearly explained and the icon of "Agree to participate" was a condition for proceeding in responding to the questionnaire items.

\section{Disclosure}

All authors reported no conflicts of interest for this work. 


\section{References}

1. Backer J, Klinkenberg D, Wallinga J. Incubation period of 2019 novel coronavirus (2019-nCoV) infections among travellers from Wuhan, China, 20-28 January 2020. Eurosurveillance. 2020;25 (5):2000062. doi:10.2807/1560-7917.es.2020.25.5.2000062

2. Bhagavathula A, Aldhaleei W, Rahmani J, Mahabadi M, Bandari D. Knowledge and perceptions of COVID-19 among health care workers: Cross-Sectional Study. JMIR Public Health Surveill. 2020;6(2): e19160. doi:10.2196/19160

3. Peeri N, Shrestha N, Rahman M, et al. The SARS, MERS and novel coronavirus (COVID-19) epidemics, the newest and biggest global health threats: what lessons have we learned? Int J Epidemiol. 2020;49(3):717-726. doi:10.1093/ije/dyaa033

4. MOH. Reports first case of coronavirus infection [Internet]. Ministry of health; 2020 [cited February 20, 2021]. Available from: https:// www.moh.gov.sa/en/Ministry/MediaCenter/News/Pages/News-202003-02-002.aspx. Accessed July 19, 2021.

5. Daily Updates. Saudi center for disease prevention and control [Internet]. Saudi Center for Disease Prevention and Control; 2021 [cited February 20, 2021]. Available from: https://covid19.cdc.gov.sa/ daily-updates/. Accessed July 19, 2021.

6. Holmes E, O'Connor R, Perry V, et al. Multidisciplinary research priorities for the COVID-19 pandemic: a call for action for mental health science. Lancet Psychiatry. 2020;7(6):547-560. doi:10.1016/ s2215-0366(20)30168-1

7. Pappa S, Ntella V, Giannakas T, Giannakoulis V, Papoutsi E, Katsaounou P. Prevalence of depression, anxiety, and insomnia among healthcare workers during the COVID-19 pandemic: a systematic review and meta-analysis. Brain Behav Immun. 2020;88:901-907. doi:10.1016/j.bbi.2020.05.026

8. World Health Organization (WHO). Mental health: strengthening our response. Fact sheet. Geneva: World Health Organization; April 2016. Available from: http://www.who.int/mediacentre/factsheets/ fs220/en/. Accessed June 13, 2017.

9. Spoorthy M, Pratapa S, Mahant S. Mental health problems faced by healthcare workers due to the COVID-19 pandemic-A review. Asian J Psychiatr. 2020;51:102119. doi:10.1016/j.ajp.2020.102119

10. Hall L, Johnson J, Watt I, Tsipa A, O'Connor D, Harris F. Healthcare staff wellbeing, burnout, and patient safety: a systematic review. PLoS One. 2016;11(7):e0159015. doi:10.1371/journal.pone.0159015

11. Khalid I, Khalid T, Qabajah M, Barnard A, Qushmaq I. Healthcare workers emotions, perceived stressors and coping strategies during a MERS-CoV outbreak. Clin Med Res. 2016;14(1):7-14. doi:10.3121/ cmr.2016.1303

12. Lai J, Ma S, Wang Y, et al. Factors associated with mental health outcomes among health care workers exposed to coronavirus disease 2019. JAMA Netw Open. 2020;3(3):e203976. doi:10.1001/ jamanetworkopen.2020.3976

13. Badahdah A, Khamis F, Mahyijari N. The psychological well-being of physicians during COVID-19 outbreak in Oman. Psychiatry Res. 2020;289:113053. doi:10.1016/j.psychres.2020.113053

14. Schwarzer R, Jerusalem M. Generalized self-efficacy scale. In: Weinman J, Wright S, Johnston M, editors. Measures in Health Psychology: A User's Portfolio. Causal and Control Beliefs. Windsor, UK: NFER-NELSON; 1995:35-37.

15. Al-Ruwaili M, Al-Turki Y, Alardan A. Social anxiety and its effect on self-efficacy among family medicine residents in Riyadh. J Family Med Prim Care. 2018;7(2):389. doi:10.4103/jfmpc.jfmpc_360_17

16. Milam L, Cohen G, Mueller C, Salles A. The relationship between self-efficacy and well-being among surgical residents. J Surg Educ. 2019;76(2):321-328. doi:10.1016/j.jsurg.2018.07.028
17. Rabani Bavojdan M, Towhidi A, Rahmati A. The relationship between mental health and general self-efficacy beliefs, coping strategies and locus of control in male drug abusers. Addict Health. 2011;3(3-4):111-118.

18. AlQahtani S, Murshid E, Fadel H, Kassim S. Practicing dentists' selfefficacy and associated factors in managing the treatment of adults with mental and physical disabilities: an Exploratory Cross-Sectional Study in Riyadh, Saudi Arabia. Int J Environ Res Public Health. 2017;14(12):1549. doi:10.3390/ijerph14121549

19. Topp C, Østergaard S, Søndergaard S, Bech P. The WHO-5 well-being index: a systematic review of the literature. Psychother Psychosom. 2015;84(3):167-176. doi:10.1159/000376585

20. Scholz U, Gutiérrez Doña B, Sud S, Schwarzer R. Is general self-efficacy a universal construct? Eur J Psychol Assess. 2002;18 (3):242-251. doi:10.1027//1015-5759.18.3.242

21. Rahman M, Hoque N, Alif S, et al. Factors associated with psychological distress, fear and coping strategies during the COVID-19 pandemic in Australia. Global Health. 2020;16(1):1-5. doi:10.1186/ s12992-020-00624-w

22. Greenberg N. Mental health of health-care workers in the COVID-19 era. Nat Rev Nephrol. 2020;16(8):425-426. doi:10.1038/s41581-0200314-5

23. Khanal P, Devkota N, Dahal M, Paudel K, Joshi D. Mental health impacts among health workers during COVID-19 in a low resource setting: a cross-sectional survey from Nepal. Global Health. 2020;16 (1):1-12. doi:10.1186/s12992-020-00621-z

24. Lee A, Wong J, McAlonan G, et al. Stress and psychological distress among SARS survivors 1 year after the outbreak. Can J Psychiatry. 2007;52(4):233-240. doi:10.1177/070674370705200405

25. Ding Y, Huang L, Feng C, Yang M, Zhang Y. [Depression and self-efficacy in medical residents]. Zhong Nan Da Xue Xue Bao Yi Xue Ban. 2017;42(1):83-87. Chinese. doi:10.11817/j.issn.16727347.2017.01.014

26. Shoji K, Cieslak R, Smoktunowicz E, Rogala A, Benight C, Luszczynska A. Associations between job burnout and self-efficacy: a meta-analysis. Anxiety Stress Coping. 2015;29(4):367-386. doi:10.1080/10615806.2015.1058369

27. Gulbrandsen P, Jensen BF, Finset A. Endring i mestringstillit hos sykehusleger etter kurs i klinisk kommunikasjon [Self-efficacy among doctors in hospitals after a course in clinical communication]. Tidsskr nor Laegeforen. 2009;129(22):2343-2346. doi:10.4045/tidsskr.09.0261

28. Grome L, Banuelos R, Lopez M, Nicome R, Leaming-van Zandt K. Communication course for pediatric providers improves self-efficacy. Plast Reconstr Surg Glob Open. 2018;6(10):e1964. doi:10.1097/ gox.0000000000001964

29. Maryam V, Qorbani M, Arzaghi SM, Muhidin S, Javanmard Z, Esmaeili M. The mental health of healthcare workers in the COVID-19 pandemic: a systematic review [published online ahead of print, 2020 Oct 26]. J Diabetes Metab Disord. 2020;19(2):1-12. doi:10.1007/s40200-020-00643-9

30. Tsuei S, Clair V, Mutiso V, et al. Factors influencing lay and professional health workers' self-efficacy in identification and intervention for alcohol, tobacco, and other substance use disorders in Kenya. Int J Ment Health Addict. 2017;15(4):766-781. doi:10.1007/s11469017-9775-6

31. Soudagar S, Rambod M, Beheshtipour N. Factors associated with nurses' self-efficacy in clinical setting in Iran, 2013. Iran J Nurs Midwifery Res. 2015;20(2):226-231.

32. Janko M, Smeds M. VESS13. Burnout, depression, perceived stress, and self-efficacy in vascular surgery trainees. J Vasc Surg. 2018;67 (6):e55. doi:10.1016/j.jvs.2018.03.025 


\section{Publish your work in this journal}

Risk Management and Healthcare Policy is an international, peerreviewed, open access journal focusing on all aspects of public health, policy, and preventative measures to promote good health and improve morbidity and mortality in the population. The journal welcomes submitted papers covering original research, basic science, clinical \& epidemiological studies, reviews and evaluations, guidelines, expert opinion and commentary, case reports and extended reports. The manuscript management system is completely online and includes a very quick and fair peer-review system, which is all easy to use. Visit http://www.dovepress.com/testimonials.php to read real quotes from published authors.

Submit your manuscript here: https://www.dovepress.com/risk-management-and-healthcare-policy-journal 